\title{
Factors associated with the use of seclusion in an inpatient psychiatric unit in Lilongwe, Malawi
}

\author{
Brian S. Barnett ${ }^{1,2,3}$, Veronica Kusunzi ${ }^{4}$, Lucy Magola ${ }^{4}$, Christina P.C. \\ Borba $^{5}$, Michael Udedi ${ }^{6,7}$, Kazione Kulisewa ${ }^{4}$, Mina C. Hosseinipour ${ }^{3}$ \\ 1. Department of Psychiatry, McLean Hospital; Department of Psychiatry, Harvard Medical School, Boston, \\ USA \\ 2. Vanderbilt University School of Medicine, Nashville, USA \\ 3. University of North Carolina Project, Lilongwe, Malawi \\ 4. Bwaila Psychiatric Unit, Kamuzu Central Hospital, Malawi \\ 5. Department of Psychiatry, Boston Medical Center; Boston,. University School of Medicine, 72 East \\ Concord St, Boston, USA. \\ 6. Ministry of Health, Lilongwe, Malawi \\ 7. Department of Mental Health, College of Medicine, University of Malawi, Blantyre, Malawi
}

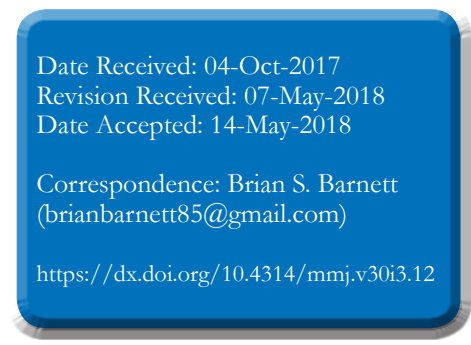

\section{Background}

\section{Abstract}

Data on the use of seclusion for psychiatric inpatients in sub-Saharan Africa are extremely limited. Though seclusion is sometimes necessary for patients that pose a threat to themselves or others, adverse physical and psychological sequelae from the experience are increasingly being recognized, leading to efforts to reduce its use. The purpose of this study was to calculate the frequency of seclusion in patients hospitalized in an inpatient psychiatric unit in Lilongwe, Malawi, and to identify factors associated with its use.

\section{Methods}

Records of 419 psychiatric inpatients hospitalized at Kamuzu Central Hospital's Bwaila Psychiatric Unit in Lilongwe, Malawi, from January 1, 2011 to December 31, 2011, were reviewed. Multivariate logistic regression analysis was employed to identify factors associated with the use of seclusion.

\section{Results}

Seclusion was used for 30.3\% (127/419) of patients during the study period. Male patients had increased odds of being secluded (aOR: 2.22, $\mathrm{p}=0.02)$. Assaulting other patients on the unit $(\mathrm{aOR} 7.92, \mathrm{p}<0.01)$ and presenting to the unit in mechanical restraints $(\mathrm{aOR} 2.33, \mathrm{p}<0.01)$ were also associated with seclusion. There was no association between seclusion and age; diagnosis of alcohol use disorder, marijuana use disorder, or schizophrenia; involuntary admission; presence of extra pyramidal side effects; presence of hallucinations; suicidality; or commission of violent acts prior to admission.

\section{Conclusions}

Documentation about the rationale for the use of seclusion on the unit was minimal. Improved record keeping requirements will be essential to future efforts to study seclusion and reduce its use. Development of strategies to address patient violence on the unit could decrease the use of seclusion for aggressive patients. Patients arriving to the unit in restraints would benefit from increased efforts by staff to apply behavioural interventions or administer medications, in order to deescalate these individuals and limit the use of seclusion in their treatment.

Key words: sub-Saharan Africa, Malawi, mental disorders, mental health, psychiatry, seclusion

\section{Introduction}

Seclusion is the act of involuntarily confining a patient to a room where they are unable to exit. It is a commonly used coercive measure in psychiatric units around the world. Other coercive measures available to treatment teams, depending on where they practice, include physical restraint (holding a patient and restricting their movement), mechanical restraint (using belts or other devices to restrict patient movement) and chemical restraint (using involuntary medications to calm or sedate a patient). This paper focuses on the use of seclusion, though other coercive measures will also be mentioned, since many studies have looked at the use of coercive measures collectively and not focused solely on seclusion. Coercive measures are not considered therapeutic modalities by professional organizations or according to government regulations ${ }^{1}$. Therefore, these interventions should only be utilized when emergency situations arise in order to prevent patients from harming themselves, harming other patients or staff, or absconding from a treatment facility. According to one study, the most common reasons for use of seclusion, in descending order, are risk of harm to others, risk of harm to self and risk of abscondment ${ }^{2}$. Behavioural interventions or voluntary medications should be offered to patients prior to the use of coercive measures, though these interventions are often not sufficient.

While coercive measures are usually required for purposes of maintaining safety, injuries can occur to both patients and staff when they are applied ${ }^{1}$. In addition to physical injuries, coercive measures have been shown to cause emotional trauma for both patients receiving them and staff members applying them ${ }^{3-7}$. Therefore, providers should use the least restrictive coercive measure that will allow them to safely manage a clinical situation in order to maximize patient liberty. When emergency situations arise, patients prefer receiving medications to seclusion and they prefer seclusion to mechanical restraint ${ }^{8}$. Patients often report that coercive measures are used to enforce discipline, or as a therapeutic modality, rather than for emergency purposes only ${ }^{1}$. These reports are probably due to a combination of perceptual differences between providers and patients, but also likely reflect misuse of coercive measures in many institutions. Even when appropriately used, there is concern that using repeated coercive measures on inpatients may make it difficult for them to learn skills required to manage distress 


\section{Methods}

Study setting

The study was conducted at Bwaila Psychiatric Unit (BPU), which is located on the grounds of Bwaila District Hospital. $\mathrm{BPU}$ is a satellite unit of the tertiary level Kamuzu Central Hospital. Located in Malawi's capital and largest city Lilongwe, BPU is designated as a tertiary level psychiatric
unit by the Ministry of Health and has a catchment area that unit by the Ministry of Health and has a catchment area that includes the nine Central Region districts of Malawi's 28
administrative districts. Despite its classification as a tertiary administrative districts. Despite its classification as a tertiary
psychiatric unit, BPU lacks many of the resources that would psychiatric unit, BPU lacks many of the resources that would
be expected to come with such a designation. BPU is the be expected to come with such a designation. BPU is the
smallest of Malawi's psychiatric facilities and has 25 beds, smallest of Malawi's psychiatric facilities and has 25 beds, which are divided into a male unit ( 14 beds) and a female uni (11 beds). It frequently operates above its intended capacity, averaging approximately forty admissions at any point. The male and female wards have four single rooms each, which inve locked from the outside and are sometimes used for and housed so the units in Malawi, BPU primarily treats patients who are

Care at BPU is administered through Malawi's government health system and during the study period care was provided by two registered psychiatric nurses, who had undertaken degree training course in psychiatric care at St. John of God College of Health Sciences in Mzuzu, and several enrolled psychiatric nurses, who had undertaken a diploma training course in psychiatric care at Malawi College of Health sciences in Zomba. In addition to caring for the inpatien population, the nurses also saw outpatients daily. There were no mental health clinicians based at BPU during the study period, but the nurses received periodic supervisio based at Zomba Mental Hospital. Treatment for patients BPU is limited to almost entirely psychopharmacologic therventions. During the study period, medication option at BPU were much more limited than at the country's other acilities, with antipsychotics being constrained to only firs generation type. ${ }^{21} \mathrm{BPU}$ is also less adequately staffed than the ther psychiatric facilities, which creates further challenges

During the study period, staff at BPU had not received aggression management training. However, since the study concluded, staff members have participated in training faclitated by staff from Zomba Mental Hospital. Patients at BPU with behavioural difficulties that are not responsive to redirection by staff are typically offered voluntary dysregulation is managed through either chemical restrain with involuntary intramuscular or intravenous administration of medications, or involuntary seclusion, rather than physical or mechanical restraint. Due to medication shortages, chemical restraint is often not a realistic possibility. If a patient refuses to enter the seclusion room on their own, nurses and patient attendants will hold the patient and move them into the room. Once in seclusion, patients are typically observed at meal times, medication administration times and during staff handover periods. Patients are released from

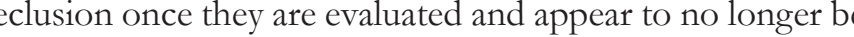
themselves or others.

Malawi's Mental Treatment Act (Chapter 34:02) of 19482 which provides the legal framework for mental health treatment within the country, does not address seclusion or dictate regulatory requirements surrounding its use. The Malawi Mental Health Bill of $2004^{23}$ included the following proposed seclusion regulations: Seclusion and restrain should only be utilized in exceptional cases to prevent immediate danger or imminent harm to self or others. The maximum duration of seclusion should be six hours. 15 minute observations by staff are required once seclusion has in a register. The use of seclusion must be documented the duration. Seclusion rooms must be well ventilated and have sufficient light. A centralized review body will receive periodic reports of all secluded patients. However, this bill was not passed into law, so the use of seclusion in Malaw remains unregulated. There is no formal protocol at BPU of seclusion, how frequently secluded patients should be assessed, or when to release patients from seclusion. If patients are secluded, this fact is typically recorded in charts though information regarding who ordered the seclusion, seclusions per admission is not usually included.

\section{Study design}

We conducted a retrospective review of charts for patient who were hospitalized at BPU from January $1^{\text {st }}$ through December $31^{\text {st }}, 2011$. Rather than calculating a require sample size for our analysis before the study initiation, we chose to evaluate the unit population over a one-year perio of time. Data including socio-demographic characteristics (age, gender, living situation, marital status, etc.), diagnoses, patient behaviours (suicidal ideation, suicide attempts, homicidal ideation, assault of other patients, etc.), length cay , and outer recorded as they were witeren in the chart and were based The

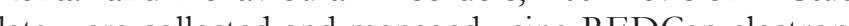
data were collected and managed using REDCap electronic

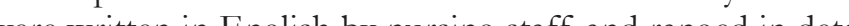

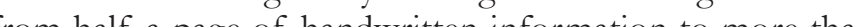
ten pages, with the average chart length being approximately five pages.

\section{Data analysis}

During the study period, chart documentation was available for 419 patients. There were 29 patients readmitted during the study period for a total of 33 times. For patients who were readmitted, data from only one admission were used in statistical modelling to prevent duplication of data and to maintain independence of observations. These data usually came from the first admission during the study period. However, for patients that were secluded, data from the admission in which seclusion occurred were used in statistical modelling. One patient was secluded in his initia admission and readmission. For this individual, data from the initial admission were utilized. Due to missing data, the total sample size was less than 419 for many variables that were assessed. All statistical analyses were conducted using Stata $^{\circledR}$ version 12.0 (Stata Corporation, College Station, Texas, USA).

Bivariate testing of patient variables and seclusion was conducted using Student's t-test (two sided) for continuous variables and Pearson's chi-squared test for categorical variables. Multiple logistic regression was used to test for associations between patient variables and seclusion. Independent variables were chosen based on the finding of previous research and clinical relevance. The model was checked to ensure that assumptions of logistic regression were met. Pearson goodness of fit testing of the mode produced a Chi-squared test statistic of 342.33 and a p-value of 0.26 , indicating sufficient goodness of fit. Statistica significance for all tests was declared at a p-value of $<0.05$.

Ethical approval

The study proposal was approved by the Malawi Nationa Health Science Research Committee and the University North Carolina, Chapel Hill Institutional Review Board.
Seclusion of psychiatric inpatients 199

\begin{tabular}{|c|c|c|}
\hline Satient variable & & $n,(\%)$ \\
\hline \multicolumn{3}{|l|}{ Sender $(N=414)$} \\
\hline & Male & $302(73.0)$ \\
\hline & Female & $112(27.0)$ \\
\hline \multicolumn{3}{|l|}{$\begin{array}{l}\text { Marital status } \\
\mathrm{N}=372 \text { ) }\end{array}$} \\
\hline & Married & $116(31.2)$ \\
\hline & Single & $256(68.8)$ \\
\hline \multirow{2}{*}{\multicolumn{3}{|c|}{$\begin{array}{l}\text { iving situation } \\
(\mathrm{N}=188)\end{array}$}} \\
\hline & With partner & $94(50.0)$ \\
\hline & With others & $78(41.5)$ \\
\hline & Alone & $16(8.5)$ \\
\hline \multicolumn{3}{|l|}{ Education (N=257) } \\
\hline & $\begin{array}{l}\text { None } \\
\text { Completed Standard } 8 \text { or }\end{array}$ & $12(4.7)$ \\
\hline & $\begin{array}{l}\text { less } \\
\text { Completed Form } 1 . \| \mathrm{III}\end{array}$ & $131(51.0)$ \\
\hline & or IV & $103(40.1)$ \\
\hline \multirow{7}{*}{$\begin{array}{l}\text { Employment type } \\
\mathrm{N}=318 \text { ) }\end{array}$} & Any university & $11(4.3)$ \\
\hline & No formal employment & $102(32.1)$ \\
\hline & Farmer & $60(18.9)$ \\
\hline & Laborer & $43(13.5)$ \\
\hline & Vendor & $37(11.6)$ \\
\hline & Student & $34(10.7)$ \\
\hline & Other & $42(13.2)$ \\
\hline \multirow{3}{*}{ Religion $(\mathrm{N}=359)$} & Christian & $279(77.7)$ \\
\hline & Muslim & $22(6.1)$ \\
\hline & Other & $58(16.2)$ \\
\hline \multirow{3}{*}{$\begin{array}{l}\text { Existing psychiatric } \\
\text { liagnosis }(N=381)\end{array}$} & & \\
\hline & Yes & $248(65.1)$ \\
\hline & No & $133(34.9)$ \\
\hline \multirow{2}{*}{ 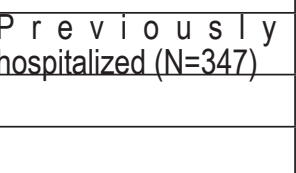 } & & \\
\hline & No & $151(43.5)$ \\
\hline \multirow{7}{*}{$\begin{array}{l}\text { s y c c i a t r i c } \\
\text { liagnoses }{ }^{*}(N=419)\end{array}$} & & \\
\hline & Schizophrenia & $126(30.1)$ \\
\hline & Cannabis use disorder & $117(27.9)$ \\
\hline & Alcohol use disorder & $105(25.1)$ \\
\hline & $\begin{array}{l}\text { Epileptic psychosis } \\
\text { Maior } \\
\text { depressive }\end{array}$ & $30(7.2)$ \\
\hline & disorder & $28(6.7)$ \\
\hline & Other & $59(14.1)$ \\
\hline
\end{tabular}

\section{*Percentage sums to grea
having multiple diagnoses}

\section{Results}

The study population was $73.0 \%$ male $(303 / 415)$ and the mean age was $29.6 \pm 9.5$ years old (range: 10-74). The mean length of hospitalization on the unit was $22.2 \pm 28.1$ described in table 1 .

The predominant diagnoses were schizophrenia $30.1 \%$ 


\begin{tabular}{|l|l|l|l|l|}
\hline \multicolumn{5}{|l|}{ Table 2: Bivariate analysis of patient variables and seclusion } \\
\hline Variables & $\begin{array}{l}\text { Whole sample } \\
\%(\mathrm{n} / \mathrm{N})^{*}\end{array}$ & $\begin{array}{l}\text { Secluded } \\
\%(\mathrm{n} / \mathrm{N})^{*}\end{array}$ & $\begin{array}{l}\text { Not secluded } \\
\%(\mathrm{n} / \mathrm{N})^{*}\end{array}$ & P-value \\
\hline Age [in years] (n=395) & $29.6 \pm 9.5$ & $28.1 \pm 7.4$ & $30.2 \pm 10.2$ & 0.04 \\
\hline Assault on other patients & $5.6(23 / 414)$ & $12.8(16 / 125)$ & $2.4(7 / 289)$ & $<0.01$ \\
\hline Diagnosis of alcohol use disorder & $25.1(105 / 419)$ & $27.6(35 / 127)$ & $24.0(70 / 292)$ & 0.44 \\
\hline Diagnosis of marijuana use disorder & $27.9(117 / 419)$ & $33.9(43 / 127)$ & $25.3(74 / 292)$ & 0.07 \\
\hline Diagnosis of schizophrenia & $30.1(126 / 419)$ & $25.2(32 / 127)$ & $32.2(94 / 292)$ & 0.15 \\
\hline Extrapyramidal side effects present & $13.2(55 / 418)$ & $10.2(13 / 127)$ & $14.4(42 / 291)$ & 0.24 \\
\hline Hallucinations of any type & $21.1(87 / 413)$ & $21.0(26 / 124)$ & $21.1(61 / 289)$ & 0.98 \\
\hline Involuntary admission & $94.2(386 / 410)$ & $93.6(116 / 124)$ & $94.4(270 / 286)$ & 0.73 \\
\hline Male gender & $73.0(302 / 414)$ & $83.2(104 / 125)$ & $68.5(198 / 289)$ & $<0.01$ \\
\hline Mechanically restrained upon admission & $31.6(130 / 411)$ & $44.4(55 / 124)$ & $26.1(75 / 287)$ & $<0.01$ \\
\hline Suicidality reported at admission & $4.8(20 / 416)$ & $7.9(10 / 126)$ & $3.5(10 / 290)$ & 0.05 \\
\hline $\begin{array}{l}\text { Violent acts/physical } \\
\text { aggression prior to admission }\end{array}$ & $72.1(302 / 419)$ & $74.0(94 / 127)$ & $71.2(208 / 292)$ & 0.56 \\
\hline *Total number of patients per variable varies slightly due to missing data. & & \\
\hline
\end{tabular}

\begin{tabular}{|l|l|l|l|}
\hline \multicolumn{5}{|l|}{ Table 3: Multiple logistic regression of patient variables and seclusion } \\
\hline Variables & Coefficient (S.E.) & Odds ratio (95\% Cl) & P-value \\
\hline Age & $-0.02(0.01)$ & $0.98(0.96-1.01)$ & 0.23 \\
\hline Assault on other patients during admission & $2.07(0.53)$ & $7.92(2.82-22.18)$ & $<0.01$ \\
\hline Diagnosis of alcohol use disorder & $-0.11(0.31)$ & $0.89(0.48-1.65)$ & 0.72 \\
\hline Diagnosis of marijuana use disorder & $0.14(0.32)$ & $1.16(0.61-2.17)$ & 0.65 \\
\hline Diagnosis of schizophrenia & $-0.40(0.31)$ & $0.67(0.37-1.23)$ & 0.20 \\
\hline Extrapyramidal side effects during admission & $-0.39(0.38)$ & $0.67(0.32-1.43)$ & 0.30 \\
\hline Hallucinations of any type & $0.15(0.29)$ & $1.16(0.65-2.07)$ & 0.61 \\
\hline Involuntary admission & $-0.31(0.55)$ & $0.74(0.25-2.15)$ & 0.58 \\
\hline Male gender & $0.80(0.33)$ & $2.22(1.15-4.27)$ & 0.02 \\
\hline Mechanically restrained upon admission & $0.85(0.25)$ & $2.33(1.43-3.82)$ & $<0.01$ \\
\hline Suicidality reported at admission & $0.93(0.54)$ & $2.53(0.87-7.31)$ & 0.09 \\
\hline Violent acts/physical aggression prior to admission & $0.06(0.30)$ & $1.06(0.60-1.90)$ & 0.84 \\
\hline Constant for statistical model & $-1.09(0.68)$ & $0.34(0.09-1.28)$ & 0.11 \\
\hline
\end{tabular}

\section{Discussion}

This one-year study of a cohort of Malawian psychiatric inpatients revealed that $30.3 \%$ of patients were secluded an demonstrated three patient factors associated with the use of seclusion: male gender, arriving to the facility in mechanica restraints, and assaulting other patients on the unit. These findings indicate two possible areas for intervention to reduce the use of seclusion: implementation of strategies to reduce patient violence and increased efforts to ensure that staff members thoughtfully assess the need for seclusion in patients arriving in restraints.

The frequency of seclusion at BPU is similar to that reported in developed countries, which ranges from $23 \%$ to $35 \%$, ${ }^{2,14,15}$ The only known study reporting a frequency for the use of coercive measures in sub-Saharan Africa was conducted in Harare, Zimbabwe in 1998 and found that $8.5 \%$ of psychiatric inpatients were secluded or restrained. One factor that might have accounted for the decreased use of seclusion in that study is more scrutiny of the use Health Health Act, which was passed in 1996. ${ }^{27}$ The law requires that coercive measures only be used upon the order of the superintendent of an institution. A daily register detailing reasons for use of coercive measures and the duration of those measures is also required. A copy of this register must then be submitted to the Ministry of Health and Child Care on a quarterly basis. Changes to legal policies ${ }^{28}$ focusing on who can order seclusion, what its indications are, and how long/often it can be used, have been instrumental to decreasing the use of coercive measures around the world. Given that Malawi has no legal requirements for the use of coercive measures, legislative efforts to implen

Assaulting other patients was the factor within our study population that most increased risk of seclusion. $\Lambda$ te least $5.6 \%$ of patients committed acts of violence on the unit during the study period. Given the unit's limited recordkeeping, the actual percentage may be significantly higher. Therefore, efforts to decrease violence on the unit are essential to protecting patients and staff members, as well as decreasing the amount of time spent in seclusion by perpetrators. A recent comprehensive review demonstrated that $17 \%$ of patients will commit at least one act of violence on an inpatient psychiatric unit. ${ }^{29}$ A study of aggressive episodes in an Irish psychiatric unit found that triggers for violence were not observed $63 \%$ of the time, while $21 \%$ of episodes occurred following denial of patient requests by staff, $11 \%$ occurred due to provocation by another patien and $4 \%$ occurred after staff asked the patient to take medication..$^{30}$ In that study, aggression was aimed at ward staff $63 \%$ of time, at other patients $36 \%$ of time, and was self-directed $2 \%$ of the tim

Research on inpatient violence in African psychiatric units has been minimal, with a South African study of long term psychiatric patients demonstrating that $16 \%$ of patients were violent on the unit and that physical aggression between patients accounted for $58 \%$ of violent incidents. Risks factors for violence in that study included lack of disorganized behaviour, longer stay, mental retardation, first hospitalization before age 40 , and habitual verbal aggression. "No association was found between gender and violence in that study. However, another study of psychiatric more likely to be carried out by men, and that men were also more likely to be secluded. ${ }^{2}$ However, a study from Zimbabwe demonstrated that females were more assaultive towards other patients and staff than male patients. ${ }^{19}$ A Nigerian study revealed that half of staff members working on a psychiatric unit had been assaulted by atient at least once.

Studies of inpatient psychiatric unit violence in the developed world have found associations with the following atient factors: involuntary treatment status $^{29,33}$, diagnosis
of alcohol use disorder ${ }^{2}$, past violent behaviour
33-35, verbal or physical aggression against people or objects in the month prior to admission ${ }^{35}$, antisocial personality disorder ${ }^{33}$ borderline personality disorder ${ }^{33}$, past self harm $^{33}$, and substance abuse. ${ }^{33}$ Unit factors associated with violence include frequent medication changes $^{33}$, increased use of sedative drugs ${ }^{33}$, and long hospitalization. ${ }^{33}$ One review also noted associations between violence and several staff factors including staff member age, length of work experience, prevention and management of patient assaults.

Given the dearth of research on inpatient violence and use of seclusion in developing countries in sub-Saharan Africa and elsewhere, it is difficult to make comparisons with developed countries about rates of inpatient violence and seclusion, as well as associated factors. Variations in patient populations and partially account for differences in inpatient violence For example, involuntary status has been associated with both inpatient violence and use of seclusion in developed ountries. We found no association with seclusion and involuntary status. This might be explained by the high level of patients who were involuntary hospitalized at BPU $\left(94.2^{2} \%\right)$ compared to $5-30 \%$ in developed countries. ${ }^{36}$ There are also differences in our population and inpatient populations in developed countries in terms of diagnostic composition. While schizophrenia, cannabis use disorder and alcohol use disorder were the most common diagnoses at BPU, in developed countries mood disorders are typically the most common diagnoses on inpatient units and anxiety disorders are also much more prevalent. ${ }^{3}$.

It is unclear why patients in our study who arrived in mechanical restraints were more likely to be secluded. Because circumstances of seclusion were not recorded in patient charts, we can only speculate about why this may be. Patients arriving in restraints may be more likely to behave it may have been possible that staff simply secluded these individuals upon arrival due to concern that they would act aggressively because they were already in restraints, which would not be appropriate use of seclusion. Staff may also have been more likely to seclude these patients since they may have also been more likely to attempt to abscond, which is a challenge for the unit, as 3.4\% of patients absconded during the study period.

Overall, the lack of record keeping requirements makes the study of seclusion in Malawi a challenge. Standardized seclusion reporting methods in numerous countries have mproved information gathering about seclusion an Malawi would benefit from required documentation of seclusion that details the incident leading up to seclusion, 
the indication for seclusion, the amount of time spent in the lack of documentation requirements concerning the use seclusion and efforts used to prevent the use of seclusion, of seclusion, future studies would be most useful if the such as offering voluntary medications or employing behavioral interventions. ${ }^{39}$

Decreasing the use of seclusion often requires a multifaceted approach that employs policy modifications, as well as interventions implemented at the unit level. Staff members are more likely to use seclusion if they perceive that workplace safety measures on the unit are inadequate, there is a higher level of order and organization among unt staff. ${ }^{40}$ Efforts to educate staff on how to identify impendin violence, how to use verbal de-escalation techniques, an how to divert patients' attention when they are agitated are especially useful for decreasing seclusion. Changing staffpatient assignments regularly, so that staff members alternate between caring for patients with severe illness and caring for those with milder illness, can also lead to decreased use of coercive measures. ${ }^{2}$

Strategies to systematize the decision-making process for using seclusion are also important, since there is often much disagreement among staff about when to actually to suggest secluding patients ${ }^{1}$ so it is essential to include veteran providers in the decision making process. Team based decision making efforts are preferable, since one stud demonstrated that some staff members are consistently appointed to make coercive measure decisions, which can lead to increased use if there are no checks provided by other individuals. ${ }^{41}$ Furthermore, misconceptions among staff may exist about when coercive measures are indicated ${ }^{42}$ and ca increase their use, so staff knowledge should be assessed and deficiencies corrected.

Research on reducing the use of seclusion has found a variety of other potential tactics for psychiatric units to employ. One prospective, randomized study found that making inexpensive changes to a unit's physical environment, along with holding regular staff-patient group meetings on the unit, reduced the that regular review of cases where coercive measures were used, and the development of targeted treatment plans for secluded patients, resulted in a $75 \%$ reduction in the use of coercive measures by the end of the five year study period. Patients have also sugrested that in order to reduce the use of coercive measures, that nurses speak to them in a calm voice, sincerely listen to their concerns, allow them to participate in the decision-making process for their treatment an provide them with meaningful activities to pass the time..$^{39} \mathrm{~A}$ randomized controlled trial demonstrated that administerin involuntary psychiatric medications to patients who were a risk of harm to themselves or others decreased their risk of being secluded. However, it did not decrease the duration of seclusion incidents when they occurred or the total number of coercive incidents. ${ }^{44}$ Another study found that focusing on early recognition of agitation and intervening quickly, once it is observed, resulted in a $52 \%$ decrease in seclusion and restraint. ${ }^{45}$ However, that study also found that assault on staff and other patients increased dramatically, indicating the importance of cau

Patients within Malawi's mental healthcare system would benefit from further research investigating both patientrelated and staff-related factors in the use of seclusion. Given were conducted in a prospective manner to avoid problems with missing data. Additionally, for a better understanding of seclusion throughout the country, future studies would be most useful if they included a representative sample from all of the country's inpatient psychiatric

\section{imitations}

The lack of documentation requirements concerning seclusion in Malawi is the primary limitation of our study, Cong with its retrospective design and resultant missing data. Consequently, it is possible that the frequency of seclusion There is also in this cohort may have been underreported. There is also concern about the validity of patient diagnoses, dison the lack of patients admitted for primary affective disorders or affective psychoses. There is also a limitation in

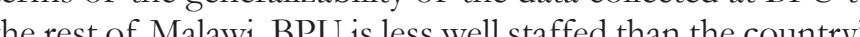
other psychintric facilities and employed no clinical officers psychintrists during the study period. It also had more limited medication options, as well as medication shor during that time. Therefore, it is possible that secluion the other facilities might differ significantly from that of BPU.

\section{Conclusion}

As in other psychiatric facilities around the world, seclusion is commonly used at BPU. Male gender, arriving to the unit in mechanical restraints, and assaulting other patients are patient factors associated with increased risk of seclusion at from the development of legal policies to direct the use of seclusion and associated documentation requirements. Improved documentation would provide rationale about the use of seclusion and better inform strategies to reduce its use. Staff education about appropriate use of seclusion and fforts to create a standardized, team-based decision-making process for the use of seclusion may also prove helpful in escalate tits utilization. Finally, efforts to identify and deuse of behavioural interventions or voluntary medications, would also likely decrease the use of seclusion. However, any efforts to reduce its use should also ensure that there are no increases in
as a result.

\section{Acknowledgements}

This work was supported by funding from the University Institutes of Health (NIH) funded program (grant P30 Mental Health was supported by a National Institute of KK was supported by an NIH intent grant (K01MHio0428). KK was supported by an NIH international research training Fogarty Fellowship in Public Health (2011-12) sponsor hrough a partnership between the Fulbright program ar he NIH through the Fogarty International Clinical Resean Scholars and Fellows Program at Vanderbilt Univers (grant R24 TW007988). MU was supported by funding from the African Mental Health Research Initiative (grant DEL 15-01) We thank the administration, patients and staff of BPU fo BPU. Patients at BPU and throughout Malawi would benefit of North Carolina Center for AIDS Research, a Nationa
Laura Ball and Travis Tressler for their assistance with

\section{Conflict of interest}

The authors have no conflicts of interest to report

\section{References}

1. Busch $A B$, Shore MF. Seclusion and restraint: a review of recent hiterature. $\mathrm{H}$.5.261

2. Tunde-Ayinmode M, Little J. Use of seclusion in a psychiatric acute inpatient unit. Australas $P$.

3. Bonner G, Lowe T, Rawcliffe D, Wellman N. Trauma for all: a pilo study of the subjective experience of physical restraint for mental 2002;9(4):465-473. doi:10.1046/j.1365-2850.2002.00504.x

4. Moran A, Cocoman A, Scott PA, Matthews A, Staniuliene V, Valimaki M. Restraint and seclusion: a distressing treatment option?

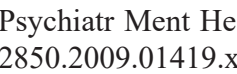

5. Fisher WA. Restraint and seclusion: a review of the literature. Am J Psychiatry. 1994:151(11):1584-1591, doi:10.1176/ajp.151.11.1584

6. Frueh BC, Knapp RG, Cusack KJ, et al. Patients' reports of traum or harmful experiences within the psychiatric setting. Psychiatr Serv.

7. Soliday SM. A comparison of patient and staff attitudes toward seclusion. J Nerv Ment Dis. 1985;173(5):282-29

8. Sheline Y, Nelson T. Patient choice: deciding between psychotropic medication and physical restraints in an emergency. Bull Am Acad Psychiatry Law. 1993;21(3):321-329.

9. Donat DC. An analysis of successful efforts to reduce the use of seclusion and restraint at a public psychiatric hospital. Psychiatr Serv 2003;54(8):1119-1123. doi:10.1176/appi.ps.54.8.1119

10. Allen MH, Currier GW. Use of restraints and pharmacotherapy in academic psychiatric emergency services, Gen Hosp Psychiatry. 2004;26(1):42-49.

11. Funk M, Drew N. Strategies to end the use of seclusion, restraint and other coercive practices - Training to act, unite and empower for mental ealth. Genevea (Switzerland): Mental Health Policy and Service World Health Organization; 2017. Available from: http://apps.who.in iris/bitstream/10665/254809/1/WHO-MSD-MHP-17.9-eng.pdf.

12. Sailas E, Wahlbeck K. Restraint and seclusion in psychiatric inpatien wards. Curr Opin Psychi

13. Kalisova L, Raboch J, Nawka A, Sampogna G, Cihal L, Kallet TW, et al. Do patient and ward-related characteristics influence the sults from the EUNOMIA internationa study. Soc Psychiatry Psychiatr Epidemiol. 2014;49(10):1619-1629. doi:10.1007/s00127-014-0872-6

14. Husum TL, Bjorngaard JH, Finset A, Ruud T. A cross-sectional prospective study of seclusion, restraint and involuntary medication in acute psychiatric wards: patient, staff and ward characteristics.
Health Serv Res. 2010;10(89). doi:10.1186/1472-6963-10-89

15. Dumais A, Larue C, Drapeau A, Menard G, Giguere AM. Prevalence and correlates of seclusion with or without restraint in a Canadia psychiatric hospital: a 2-year retrospective audit. J Psychiatr Ment Heal
Nurs. 2011;18(5):394-402. doi:10.1111/j.1365-2850.2010.01679.x 16. Swett C. Inpatient seclusion: description and causes. Bull Am Aca Psychiatry Law. 1994:22(3):421-430.
Cullen AE, Bowers L, Khondoker M, Pettit S, Achilla E, Koeser

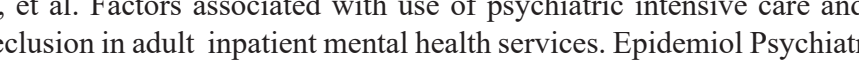
Sci. 2018;27(1):51-61. doi:10.1017/S2045796016000731

18. Georgieva I, Vesselinov R, Mulder CL. Early detection of risk factors for seclusion and restaint. a prospective study. Early Interv Psychiatry. 2012;6(4):415-422. doi:10.1111/j.1751-7893.2011.00330.x

9. Sebit MB, Siziya S, Acuda SW, Mhondoro E. Use of seclusion and Zimbabwe: gender differences. Cent Afr J Med. 1998;44(11):277-280.

20. Luckhoff M, Jordaan E, Swart Y, Cloete KJ, Koen L, Niehaus DJH. Retrospective review of trends in assaults and seclusion at an acute 2013;20(8):687-695. doi:10.1111/jpm.12006

21. Kauye F, Udedi M, Mafuta C. Pathway to care for psychiatric patients in a developing country: Malawi. Int J

22. Mental Health Treatment Act (Cap. 34:02). (1948). Available from: s.//www.mindbank info/item/931.

23. Malawi Mental Health Bill. (2004). 24. World Health Organization. The ICD-10 Classification of Mental
and Behavioural Disorders. Geneva (Switzerland): World Health Organization; 1993

25. Harris PA, Taylor R, Thielke R, Payne J, Gonzalez N, Conde G. Research electronic data capture (REDCap)--a metadata-driven
methodology and workflow process for providing translational research informatics support. J Biomed Inform. 2009;42(2):377-381 (2.110.1016/j.jbi.2008.08.010

26. Barnett BS, Kusunzi V, Magola L, Borba CPC, Udedi M, Kulisewa $\mathrm{K}$, et al. Description of the inpatient population and care received at a psychiatric unit in Lilongwe, Malawi. Int J Cult Ment Health. 2018:1-9.

27. Chapter 15:12 Mental Health Act. (1996). Available from: http:/ .

28. Gaskin CJ, Elsom SJ, Happell B. Interventions for reducing the Psychiatry. 2007:191(4):298-303. doi:10.1192/bjp.bp.106.034538

29. Iozzino L, Ferrari C, Large M, Nielssen O, de Girolamo G. Inpatients: A Systematic Review and Meta-Analysis PLoS One. 2015;10(6):e0128536. doi:10.1371/journal.pone.0128536

30. Cohen DP, Akhtar MS, Siddiqui A, Shelley C, Larkin Conal, Kinsella A, et al. Aggressive incidents on a psychiatric intensive care unit.
Psychiatr Bull. 2008;32(12):455-458, doi:10.1192/pb.bp.107.015412

31. Kruger C, Rosema D. Risk factors for violence among long-term psychiatric in-patients: a comparison between violent and non-violen

2. Ukpong DI, Owoeye O, Udofia O, Abasiubong F, Ukpong S Violence against mental health staff: a survey in a Nigerian psychiatric nd correlates of violence among . Psychiatr Serv. 2001,52(1):750. doi:10.1176/appi.ps.52.1.75

44. Chou KR, Lu RB, Chang M. Assaultive behavior by psychiatric in-patients and its related factors. J Nurs

35. Amore M, Menchetti M, Tonti C, Scarlatti F, Lundgren E, Esposito W, et al. Predictors of violent behavior among acute psychiatric
patients: clinical study. Psychiatry Clin Neurosci. 2008;62(3):247-255. doi:10.1111/j.1440-1819.2008.01790.x

36. Salize HJ, Dreßing H, Peitz M. Compulsory Admission and 
Involuntary Treatment of Mentally Ill Patients - Legislation and Practice in EU-Member States. Mannheim (Germany): European Commission Health \& Consumer Protection Directorate-General; 2002. Available from:http://psychrights.org/countries/EU/fp_promotion_2000 frep_08_en.pdf.

37. Kaltiala-Heino R, Laippala P, Joukamaa M. Inpatient treatment of mood disorders in the era of de-institutionalisation, depression awareness campaigns and development of new antidepressants. J Affect Disord. 2003;76(1-3):31-37.

38. Thompson A, Shaw M, Harrison G, Ho D, Gunnell D, Verne J. Patterns of hospital admission for adult psychiatric illness in England: analysis of Hospital Episode Statistics data. Br J Psychiatry. 2004;185 (4):334-341. doi:10.1192/bjp.185.4.334

39. Kaucic AM. The Use of Seclusion and Restraints in the Inpatient Psychiatric Hospital Setting: A Systematic Review of the Literature [Dissertation]. Akron (Ohio): University of Akron; 2017. Available from: http://ideaexchange.uakron.edu/honors_research_projects/488

40. De Benedictis L, Dumais A, Sieu N, Mailhot MP, Létourneau G, Tran MA, et al. Staff perceptions and organizational factors as predictors of seclusion and restraint on psychiatric wards. Psychiatr Serv. 2011;62(5):484-491. doi:10.1176/ps.62.5.pss6205_0484
41. Schreiner GM, Crafton CG, Sevin JA. Decreasing the use of mechanical restraints and locked seclusion. Adm Policy Ment Health. 2004;31(6):449-463. doi:10.1023/B:APIH.0000036413.87440.83

42. Nuhu F, Yusuf A, Aremu S. Use of restraint in the psychiatric setting: Knowledge of medical staff in a Nigerian psychiatric hospital. Niger J Psychiatry. 2010;8(1). doi:10.4314/njpsyc.v8i1.53304

43. Borckardt JJ, Madan A, Grubaugh AL, Danielson CK, Pelic CG, Hardesty SJ, et al. Systematic investigation of initiatives to reduce seclusion and restraint in a state psychiatric hospital. Psychiatr Serv. 2011;62(5):477-483. doi:10.1176/ps.62.5.pss6205_0477

44. Georgieva I, Mulder CL, Noorthoorn E. Reducing seclusion through involuntary medication: a randomized clinical trial. Psychiatry Res. 2013;205(1-2):48-53. doi:10.1016/j.psychres.2012.08.002

45. Khadivi AN, Patel RC, Atkinson AR, Levine JM. Association between seclusion and restraint and patient-related violence. Psychiatr Serv. 2004;55(11):1311-1312. doi:10.1176/appi.ps.55.11.1311 